(2) OPEN ACCESS

\title{
Recognising and managing eating disorders in the emergency department
}

\author{
Anisa Jabeen Nasir Jafar 지 1,2 Wisam Jalal Jawad Jafar, ${ }^{3}$ Emma Kathleen Everitt, ${ }^{2}$ \\ Ian Gill, ${ }^{4}$ Hannah Maria Sait, ${ }^{5}$ Jacinta Tan ${ }^{6,7}$
}

\begin{abstract}
- Additional supplemental material is published online only. To view, please visit the journal online (http://dx.doi. org/10.1136/postgradmedj2021-140253).

${ }^{1}$ The University of Manchester Humanitarian and Conflict Response Institute, Manchester, UK

${ }^{2}$ Manchester Royal Infirmary Department of Emergency Medicine, Manchester, UK

${ }^{3}$ Stockport NHS Foundation Trust Gastroenterology Service, Stockport, UK

${ }^{4}$ Greater Manchester Mental Health NHS Foundation Trust, Manchester, UK

${ }^{5}$ Stockport NHS Foundation

Trust, Stockport, UK

${ }^{6}$ Child and Adolescent Eating

Disorders Service (CAEDS), Oxford Health NHS Foundation

Trust, Oxford, UK

${ }^{7}$ Welsh Government Eating Disorder Service Review lead, Scottish Government Eating Disorder Service Review co-lead, Aneurin Bevan University Health Board, Newport, UK
\end{abstract}

\section{Correspondence to}

Dr Anisa Jabeen Nasir Jafar, The University of Manchester Humanitarian and Conflict Response Institute, Manchester, Manchester, UK;

anisa.jafar@nhs.net

Received 12 April 2021

Accepted 23 November 2021

Check for updates

(C) Author(s) (or their employer(s)) 2021. Re-use permitted under CC BY-NC. No commercial re-use. See rights and permissions. Published by BMJ.

To cite: Jafar AJN, Jafar WJJ, Everitt EK, et al.

Postgrad Med J Epub ahead of print: [please include Day Month Year]. doi:10.1136/

postgradmedj-2021-140253

\section{ABSTRACT}

Compared with other mental health conditions or psychiatric presentations, such as self-harm, which may be seen in emergency departments, eating disorders can seem relatively rare. However, they have the highest mortality across the spectrum of mental health, with high rates of medical complications and risk, ranging from hypoglycaemia and electrolyte disturbances to cardiac abnormalities. People with eating disorders may not disclose their diagnosis when they see healthcare professionals. This can be due to denial of the condition itself, a wish to avoid treatment for a condition which may be valued, or because of the stigma attached to mental health. As a result their diagnosis can be easily missed by healthcare professionals and thus the prevalence is underappreciated. This article presents eating disorders to emergency and acute medicine practitioners from a new perspective using the combined emergency, psychiatric, nutrition and psychology lens. It focuses on the most serious acute pathology which can develop from the more common presentations; highlights indicators of hidden disease; discusses screening; suggests key acute management considerations and explores the challenge of mental capacity in a group of high-risk patients who, with the right treatment, can make a good recovery.

\section{BACKGROUND}

The death of a teenager with an eating disorder in the UK in 2012 prompted a Parliamentary and Health Service Ombudsman's 2017 report which noted 'missed opportunities to prevent her from deteriorating'. ${ }^{1}$ Following from that, in 2020, The Royal College of Emergency Medicine subsequently issued a safety alert highlighting the high mortality rate of anorexia nervosa (AN); the risk of sudden AN death; evasion of early warning score detection; and illness, such as sepsis, being masked by absent physiological response. ${ }^{2}$

Young people with eating disorders appear to visit the emergency department (ED) significantly more often than those without, presenting the opportunity to recognise either a new diagnosis or a deterioration. ${ }^{3}$ In a US study, gastrointestinal (GI) and genitourinary presenting complaints were more common in young people with eating disorders, however, only 1 of the 246 patients screening positive for an eating disorder in this study actually mentioned having an eating disorder-related problem on initial presentation. ${ }^{3}$ A high level of vigilance for the diagnosis creates an opportunity for more successful early intervention. ${ }^{4}$
An Australian study suggests low perceived confidence among the vast majority of clinicians when dealing with eating disorders. ${ }^{5}$ A UK study of general practice (GP) referrals also found a wide variation in referral patterns, with more from practices with female GPs and those with Membership of the Royal College of General Practice qualifications. ${ }^{6}$ This low confidence and variation of detection may be due to lack of curriculum attention to eating disorders. In the UK, undergraduate medical education spends less than 2 hours on the subject, a finding that triggered calls for urgent review. ${ }^{7} \mathrm{~A}$ very recent study of US ED physicians and residents echoed this lack of training and awareness of appropriate supporting resources with the vast majority in favour of improved education in this area. ${ }^{8}$

One invaluable tool in detecting undisclosed and deteriorating eating disorders is information from carers and next of kin. The current COVID-19 pandemic, which has not only increased eating disorder morbidity but created a constraint that friends and relatives should not attend hospital appointments with patients, presents a new and very real risk of missing this vital narrative due to visitor restrictions and therefore unaccompanied patients. ${ }^{910}$

\section{PURPOSE OF REVIEW AND METHODS}

A limited search of the literature was undertaken to identify papers on eating disorders specific to acute practice in the ED. First, the top 16 emergency medicine (EM) journal sites (according to the journal ranking site www.scimagojr.com) were searched for the terms "anorexia", "eating disorder", "bulimia", "binge eating" and "avoidant restrictive food intake disorder". Twenty-five relevant papers were found. This was supplemented by a PubMed ${ }^{\circledR}$ search combining derivatives of "emergency department" with the same terms. This identified an additional 23 papers. For full details of the search findings, see online supplemental appendix 1 . This focused approach to highlighting the literature provided mostly an exploration of case reports of eating disorder presentations which the EM community have identified as important and unexpected. There were no recent practice reviews in the EM literature. The case reports have informed the subsequent discussion of ED presentations. Furthermore, the team of authors from EM, gastroenterology, psychiatry and psychology have brought together literature and experience from their specialities to provide practical support to those acutely managing eating disorder patients. 
Table 1 Eating disorder classifications

\begin{tabular}{|c|c|}
\hline ICD-11essential features only & DSM-V official features \\
\hline $\begin{array}{l}\text { Anorexia nervosa } \\
\text { Significantly low weight }\left(\mathrm{BMI}<18.5 \mathrm{~kg} / \mathrm{m}^{2}\right) / \text { rapid weight loss } \\
\text { Persistent attempt to create calorie deficit } \\
\text { Overvalued low body weight }\end{array}$ & $\begin{array}{l}\text { Anorexia nervosa } \\
\text { Significantly low weight and persistent attempt to create calorie deficit } \\
\text { Intense fear of weight gain } \\
\text { Disturbance of own body image perception }\end{array}$ \\
\hline $\begin{array}{l}\text { Bulimia nervosa } \\
\text { Frequent binge eating episodes (once a week for at least a month) } \\
\text { Repeat inappropriate compensatory behaviours to prevent weight gain (once a } \\
\text { week for at least a month) } \\
\text { Distress around bingeing/compensation } \\
\text { Not meeting anorexia nervosa definition }\end{array}$ & $\begin{array}{l}\text { Bulimia nervosa } \\
\text { Frequent binge eating episodes (around once a week for } 3 \text { months) } \\
\text { Repeat inappropriate compensatory behaviours to prevent weight gain } \\
\text { Unduly influenced by body image } \\
\text { Bingeing not exclusively during anorexia nervosa }\end{array}$ \\
\hline $\begin{array}{l}\text { Binge eating disorder } \\
\text { Frequent binge eating episodes (once a week for at least } 3 \text { months) } \\
\text { No regular compensatory behaviours to prevent weight gain } \\
\text { No medical/other mental health explanation binges } \\
\text { Distress around bingeing }\end{array}$ & $\begin{array}{l}\text { Binge eating disorder } \\
\text { Frequent binge eating episodes (at least once a week for } 3 \text { months) } \\
\text { Binges involve three or more of: eating rapidly/eating until uncomfortably full/eating } \\
\text { large amounts when not hungry/eating alone due to embarrassment over volume of } \\
\text { consumption/feeling disgusted, depressed or guilty afterwards } \\
\text { Distress around bingeing } \\
\text { No regular compensatory behaviours to prevent weight gain }\end{array}$ \\
\hline \multirow[t]{2}{*}{$\begin{array}{l}\text { Avoidant-restrictive food intake disorder } \\
\text { Avoidance/restriction of intake leading to one or both of: significant nutritional } \\
\text { consequences/negative social consequences } \\
\text { Eating pattern unrelated to body image preoccupation } \\
\text { - Unavailability of food/another illness is not a causal factor }\end{array}$} & $\begin{array}{l}\text { Avoidant-restrictive food intake disorder } \\
\text { Avoidance/restriction of intake leading to one or more of: nutritional deficiency/weight } \\
\text { loss/need for alternative feeding routes/negative social consequences } \\
\text { Unavailability of food/cultural or social norm is not a causal factor } \\
\text { Not exclusively as part of another eating disorder or with body image issues } \\
\text { If another medical/mental health condition considered related, symptoms sufficiently } \\
\text { severe to warrant specific attention }\end{array}$ \\
\hline & $\begin{array}{l}\text { Unspecified feeding or eating disorder } \\
\text { Characteristics of eating disorders however not fully fitting the diagnostic labels }\end{array}$ \\
\hline
\end{tabular}

BMI, body mass index; DSM-V, Diagnostic and Statistical Manual of Mental Disorders-5; ICD, International Classification of Diseases.

\section{DEFINITIONS AND EPIDEMIOLOGY}

There are four main eating disorders: AN, bulimia nervosa (BN), binge eating disorder and avoidant restrictive food intake disorder. ${ }^{11}$ Table 1 describes these main classifications.

Eating disorders are a range of related, often overlapping, mental health conditions which centre around abnormal attitudes to eating and the body. AN is the most familiar and dangerous of the eating disorder spectrum. Its diagnostic triad involves:

- A distorted preoccupation with body shape.

- Specific sustained behaviours enacted to reduce body weight.

- Significant weight loss. ${ }^{12}$

People with AN may severely restrict their intake or engage in bingeing with compensatory mechanisms to lose weight, such as self-inducing vomiting or misusing laxatives/diuretics. $\mathrm{BN}$ is commoner than $\mathrm{AN}$, with a similar drive to be thin, but does not fulfil the weight loss criteria for AN. However, bingeing and purging can be severe. This review refers mostly to AN/BN however its common principles can apply to the other eating disorders which are shown in table 1.

\section{The extent of the problem}

Although AN is widely considered to have the highest mortality of all psychiatric conditions, the epidemiological data is of inconsistent quality. Broadly around one-fifth of those dying do so from suicide which leaves a large proportion $(54 \%$ where the information was actually available) who die from the medical complications of eating disorders. ${ }^{13} 14$

One study estimates the prevalence of AN in the UK at $0.6 \%$ of over-16s, while BN is approximated at $1 \% .^{15}$ The eating disorders charity BEAT (beateatingdisorders.org.uk) suggests similar numbers, although their data is based on several studies alongside some baseline assumptions. ${ }^{16}$ Importantly, while the average age of onset of both of these conditions lies between 16 and 19 years, they can present at any age. Given AN's substantial mortality rate of around 20\%, ED and acute medical (AM) practitioners need to be adept at detecting, understanding and managing such a potentially fatal condition. ${ }^{13}$

\section{Underlying psychology and neurophysiology}

The development and maintenance of AN results from a combination of psychological, biological, neurological, genetic and socioenvironmental factors. ${ }^{17}$ The experience of shame of oneself has been associated with $\mathrm{AN}$, and is both positively correlated with severity and a known barrier to seeking help. ${ }^{18} 19$ Patients who develop AN can experience an 'anorexic voice' which can be powerful, negative and omnipotent. ${ }^{20}$ The strength of this 'voice' has been positively associated with childhood emotional abuse. ${ }^{21}$ This voice may also complicate the assessment process, as it may leave patients feeling anxious about being in healthcare settings and the intention of the healthcare staff they encounter. ${ }^{20}$ Externalising conversations about $\mathrm{AN}$, which locate the condition and its voice outside of the person, rather than as being a part of them, shifts the locus of volition.

Furthermore, the cognitive, emotional and behavioural effects of AN, become self-perpetuating, particularly as individuals lose weight. The longer AN is present, the more entrenched it becomes, with neurological changes contributing to this such as a grey and white matter volume loss. ${ }^{22}$ Nevertheless, research indicates that people with more severe and enduring AN can make meaningful progress in specialist treatment. ${ }^{23}$

\section{DANGER POINTS: WHEN TO SUSPECT, HOW TO SCREEN AND WHO TO ADMIT}

\section{Detecting the hidden cases}

The spectrum of potential 'flag' features is very broad especially given the hidden nature of some diagnoses. There are some patient groups where suspicion should be especially high. In particular type 1 diabetes mellitus (T1DM) presents a specific challenge as patients can deliberately misuse insulin to lose 
Box 1 Potential flags to pay attention to in uncovering a hidden diagnosis

- Typical profile: academically high-achieving young female or athlete.

- Atypical profile: increasing in males and ethnic minorities.

- Frequent abdominal pain/bloating/constipation/diarrhoea/ reflux/vomiting.

- Menstrual disturbance; subfertility; low libido.

- Unexplained cardiac arrhythmias, electrolyte disturbance, hypoglycaemia, hepatic dysfunction.

- Low pulse in the apparently athletic young person.

- Low energy fractures in young people with reduced bone mineral density.

- Agitation; microexercise around bed space.

- Warm clothes in hot weather; oversized, full coverage clothes.

- Comorbidities as a cover for weight loss:

- Coeliac disease.

- Type 1 diabetes mellitus*.

- Food allergies.

- Substance/alcohol abuse*.

*Along with personality disorders and attempted suicide these risk factors increase mortality.

weight and therefore may become regular attenders with diabetic ketoacidosis. Those with T1DM as well as AN have a much higher mortality rate than either condition on its own; possibly reflective of the paucity of expertise in managing the conditions in parallel. ${ }^{24}{ }^{25}$ Therefore, it is important to additionally screen such patients with a direct question as to whether they have been intentionally omitting insulin in order to control weight. Other features and patient profiles to be alert to are shown in box 1 .

\section{Screening tools}

The SCOFF questionnaire is widely considered to be a useful and simple screening tool for eating disorders: a score of 0 is considered to be negative for an eating disorder, a score of 2 or more indicates possible AN/BN (see box 2). ${ }^{26}$ It does need to be used with some caution however as its sensitivity is highest for $\mathrm{AN}$ and $\mathrm{BN}$ rather than the wider spectrum of eating disorders. ${ }^{26}$ Furthermore, it has been found to work best in young women. Pooled meta-analysis suggests a sensitivity of 0.86 , and while this may seem reassuring, the sensitivity was widely variable depending on study setting. ${ }^{26}$ Therefore, while there is not enough evidence to recommend it as screening-tool on its own, if positive it may prove useful especially in conjunction with other suspicious clinical features.

A useful bedside test shown in figure 1 is the Sit up-Squat Stand (SUSS) test of muscle power. ${ }^{27} \mathrm{~A}$ score of 0 on either

\section{Box 2 SCOFF Questionnaire ${ }^{26}$}

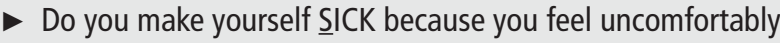
full?

- Do you worry you have lost CONTROL over how much you eat?

- Have you recently lost ONE stone in a 3-month month period?

- Do you believe yourself FAT when others say you are too thin?

- Would you say that FOOD dominates your life?

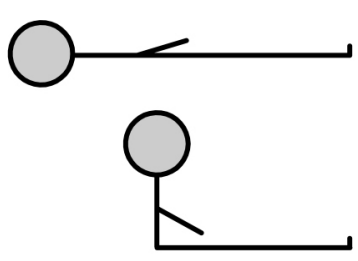

1. Sit-up: patient lies down flat on the floor and sits up without, if possible, using their hands.

Scoring (for Sit-up and Squat-Stand tests separately)

0: Unable

1: Able only using hands to help

2: Able with noticeable difficulty

3: Able with no difficulty
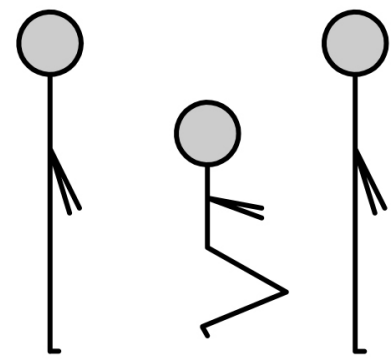

2. Squat-Stand: patient squats down and rises without, if possible, using their hands.

Figure 1 Sit up-Squat Stand test. ${ }^{27}$

element of the test denotes inability to complete the requested movement without use of hands whereas a score of 3 suggests there was no difficulty. While lacking validated evidence, this simple test for proximal muscle weakness adds some objective evidence of loss of muscle mass to a suspected and/or severe case of eating disorder, particularly if there is no other known medical cause for it.

\section{Knowing when to admit}

There is variation internationally as to what constitutes definitive admission criteria in eating disorders. Indeed the UK, at the time of writing, do not specifically define medical admission criteria.

The French admission threshold for asymptomatic adult hypoglycaemia is the equivalent of $1.7 \mathrm{mmol} / \mathrm{L}$ which appears very low. However no comment is made as to what level it would need to be corrected to in order to satisfy discharge criteria in someone who presented with asymptomatic hypoglycaemia of slightly higher than $1.7 \mathrm{mmol} / \mathrm{L}$.

In the USA, percentage $(<85 \%)$ of 'healthy' body weight is used in place of body mass index (BMI) as an indication to admit despite the DSM-V (Diagnostic and Statistical Manual of Mental Disorders-5) criteria classification of mild $\mathrm{AN}$ as a $\mathrm{BMI}>17$; moderate as a BMI 16-17; severe as a BMI 15-16 and extreme as a BMI $<15$. This classification varies from the current UK MARSIPAN guidelines which categorises a BMI of $15-17.5$ as low risk; medium as a BMI of $13-15$ and high risk as a BMI $<13$ (see table 2). ${ }^{28}$ This reflects differences in national policies regarding management of risk. It should be noted, however, that depending on the BMI status at commencement of weight loss and the rapidity of weight loss, there can be severe medical consequences even at normal or high BMIs.

Patient-reported weight may be falsely elevated and achieving a weight reading without heavy clothing (which may have 
Table 2 Medical criteria suggesting need for hospitalisation of patients with anorexia nervosa from UK, France, Australia and New Zealand and the USA

\begin{tabular}{|c|c|c|c|c|}
\hline & $\begin{array}{l}\text { UK (Marsipan, Royal Colleges } \\
\text { of Psychiatrists/ Physicians/ } \\
\text { Pathologists*) }\end{array}$ & $\begin{array}{l}\text { France (Haute Autorité de } \\
\text { Santé) }\end{array}$ & $\begin{array}{l}\text { Australia and new Zealand (Royal } \\
\text { Australian and New Zealand College of } \\
\text { Psychiatrists) }\end{array}$ & $\begin{array}{l}\text { USA (American Psychiatric } \\
\text { Association) }^{92}\end{array}$ \\
\hline BMI $\left(\mathrm{kg} / \mathrm{m}^{2}\right)$ & $<13$ (deemed high risk) & $<14$ & $<12$ & $\begin{array}{l}\text { ( }<85 \% \text { 'healthy' body } \\
\text { weight) }\end{array}$ \\
\hline Weight loss & - & $\begin{array}{l}\text { loss of } 20 \% \text { body weight in } 3 \\
\text { months }\end{array}$ & $\begin{array}{l}1 \mathrm{~kg} / \text { week over several weeks or grossly } \\
\text { inadequate nutritional intake }(<100 \mathrm{kcal} \\
\text { daily) or continued weight loss despite } \\
\text { community treatment }\end{array}$ & $\begin{array}{l}\text { Acute weight decline with } \\
\text { food refusal }\end{array}$ \\
\hline $\mathrm{HR}(\mathrm{bpm})$ & $<40$ & $\begin{array}{l}<40 \\
\text { Or } \mathrm{HR}>60 \text { at rest if } \mathrm{BMI}<13\end{array}$ & $<40$ or $>120$ & $<40$ \\
\hline Temp ${ }^{\circ} \mathrm{C}$ & $<35$ & $<35$ & $<35$ & $<36.1$ \\
\hline BP & Low & $<90 / 60 \mathrm{~mm} \mathrm{Hg}$ & $<80 \mathrm{~mm} \mathrm{Hg} \mathrm{SBP}$ & $<90 / 60 \mathrm{~mm} \mathrm{Hg}$ \\
\hline Orthostatic changes & Postural symptoms & & postural tachycardia or $>20 \mathrm{~mm} \mathrm{Hg}$ & - \\
\hline Volume status & - & Dehydration & - & Dehydration \\
\hline ECG & $\begin{array}{l}\text { QTc }>450 \text { ms, T-wave changes, } \\
\text { hypokalaemia changes }\end{array}$ & - & $\begin{array}{l}\text { Any arrhythmia, prolonged QTc or non- } \\
\text { specific ST/T changes }\end{array}$ & $\begin{array}{l}\text { Cardiovascular organ } \\
\text { compromise needing acute } \\
\text { treatment }\end{array}$ \\
\hline Blood glucose & $<3.0 \mathrm{mmol} / \mathrm{L}$ & $\begin{array}{l}\text { Symptomatic }<3.3 \mathrm{mmol} / \mathrm{L} \text { or } \\
\text { asymptomatic }<1.7 \mathrm{mmol} / \mathrm{L}\end{array}$ & $<2.5 \mathrm{mmol} / \mathrm{L}$ & $<3.3 \mathrm{mmol} / \mathrm{L}$ \\
\hline Potassium & $<3.0 \mathrm{mmol} / \mathrm{L}$ & $<3.0 \mathrm{mmol} / \mathrm{L}$ & $<3.0 \mathrm{mmol} / \mathrm{L}$ & $<3.0 \mathrm{mmol} / \mathrm{L}$ \\
\hline Sodium & $<130 \mathrm{mmol} / \mathrm{L}$ & $<125$ or $>150 \mathrm{mmol} / \mathrm{L}$ & $<125 \mathrm{mmol} / \mathrm{L}$ & Electrolyte imbalance \\
\hline Liver transaminase & Raised transaminases & Ten times normal & AST or ALT $>500$ & $\begin{array}{l}\text { Hepatic organ compromise } \\
\text { needing acute treatment }\end{array}$ \\
\hline White cells & - & $<1.0 \times 10^{9} / \mathrm{L}$ & - & - \\
\hline Neutrophils & - & $<0.5 \times 10^{9} / \mathrm{L}$ & $<1.0 \times 10^{9} / \mathrm{L}$ & - \\
\hline Magnesium & - & - & Below normal & Electrolyte imbalance \\
\hline Phosphate & - & $<0.5 \mathrm{mmol} / \mathrm{L}$ & Below normal & Electrolyte imbalance \\
\hline Renal function & Raised urea or creatinine & Creatinine clearance $<40 \mathrm{~mL} / \mathrm{min}$ & $\mathrm{eGFR}<60 \mathrm{~mL} / \mathrm{min}$ (or $25 \%$ drop in a week) & $\begin{array}{l}\text { Renal organ compromise } \\
\text { needing acute treatment }\end{array}$ \\
\hline Other & $\begin{array}{l}\text { SUSS score two or less (particularly } \\
\text { if falling) }\end{array}$ & $\begin{array}{l}\text { Hypotonia/ muscle weakness, } \\
\text { altered consciousness, intractable } \\
\text { vomiting }\end{array}$ & Albumin $<30 \mathrm{~g} / \mathrm{L}$ & Poorly controlled diabetes \\
\hline
\end{tabular}

*It should be noted that the UK do not define admission criteria as such, these are for consideration as 'high risk'.

ALT, alanine aminotransferase; AST, aspartate aminotransferase; BMI, body mass index; BP, blood pressure; eGFR, estimated Glomerular Filtration Rate; HR, heart rate; SBP, systolic blood pressure; SUSS, Sit up-Squat Stand.

deliberately heavy objects in the pockets) or prior water loading requires a good rapport and some sensitivity in approach. It is advisable for patients who are suspected to have eating disorders to be weighed in a private room in their underclothes with only a light patient gown under supervision by an appropriate healthcare professional, who takes into consideration whether the patient wishes to see or know their weight, and does not publicly announce it. Single weights provide an estimate of current weight for height status, but it is important to document weight and height so that serial measurements can be taken to ascertain trends and minimise impact of overestimation.

Each patient does need to be considered individually otherwise there is a danger of missing someone needing treatment. However guidance is fairly consistent internationally in terms of need for medical hospital admission for:

- Bradycardia of less than 40 beats per minute.

- Potassium of less than $3.0 \mathrm{mmol} / \mathrm{L}$ (unless longstanding and being adequately managed).

- Hypothermia.

- An episode of severe hypoglycaemia.

- Some evidence of renal dysfunction.

The latter is challenging to detect as low muscle mass at baseline will lead to falsely reassuring estimated glomerular filtration rates. $^{29}$
Admission should also be considered if the patient:

- Has unexplained symptoms despite normal blood tests.

- Is not showing appreciation of the gravity of their symptoms.

- Is unwilling to eat or drink more.

- Has a high risk that the symptoms will recur once sent home.

- Has insufficient support at home.

Where the risks are severe or unknown and/or patients (or carers, if underaged) appear to lack insight into the gravity of their situation, medical admission to monitor their physical state and observe their ability to eat with the intention to ask for urgent specialist eating disorder assessment, may be appropriate.

\section{CAUTIONS AND CASES FROM EATING DISORDERS PRESENTING TO THE ED}

Patients with eating disorders clearly present to the ED in a myriad of ways. They can be low, normal or high weight. Presenting problems may be primarily psychiatric, such as self injury or food and fluid refusal, however, they can also be medical. EM and AM practitioners are well versed in the standard text-book presentations such as lanugo hair, poor dentition/teeth-marks on hands from repeated induced vomiting and electrolyte disturbances. However acute clinical practice is rarely 
Box 3 Medical presentations of eating disorders

- Altered gastrointestinal tract function presenting with:

- Reflux.

- Bloating.

- Constipation.

- Non-specific abdominal pain.

- Misuse of laxatives presenting with

- Diarrhoea.

- Biochemical abnormalities.

- Mallory-Weiss tears (from frequent vomiting)

- Dizziness, syncope, fatigue, chest pain palpitations and seizures associated with:

- Electrolyte disturbance.

- Dehydration.

- Structural cardiac change.

- Significant malnutrition. ${ }^{93}$

faced with precise text-book presentations. Box 3 shows some of the wider medical presentations of an eating disorder.

Case reports in the scientific EM literature highlight some of the following more serious, and at times unexpected, features of eating disorder sequelae which may complicate management and, especially if the diagnosis is not known, delay diagnosis.

\section{Electrolyte disturbance}

- Due to long-term altered GI tract function, normally innocuous treatments, such as magnesium citrate for gastric decontamination post-overdose, can precipitate grossly deranged electrolytes shortly afterwards. ${ }^{30}$

- Severe hypokalaemia can cause cardiac arrest as a first presentation of an eating disorder in extremis. ${ }^{31}$

- Common electrolyte disorders such as hyponatraemia may not only be multifactorial and challenging to manage, but mixed advice from different inpatient teams without unifying expertise can risk cycles of failed correction. ${ }^{32}$

\section{Cardiac rhythm disturbance}

- Sinus bradycardia due to increased vagal activity (risking progression to second/third degree heart block) might be ignored as a red flag, if seemingly explained by athleticism, when in fact intensive exercise might be a vehicle for creating calorie deficit in the context of disordered eating. ${ }^{33}$

- Elevated sympathetic activity is possible, leading to tachycardia and reports of catecholamine cardiomyopathy. ${ }^{34}$

- Prolonged QT-interval may result from bradycardia, structural cardiac changes, electrolyte disturbance and concomitant QT-prolonging drugs (such as antidepressants/antipsychotics) risking progression to ventricular dysrhythmia. ${ }^{35} 36$

\section{Box 4 Challenges of assessment}

Reluctance to engage with healthcare practitioners.

- Falsification of weight and underplaying symptoms.

- Focus on physical symptoms.

- Complex capacity assessment.

- Concomitant suicide/self-harm risk.

- Misinterpretation of the illness versus wellness 'battle' as manipulative behaviour.

\section{Toxicity of purgative agents}

- Diurex ${ }^{\circledR}$ is a widely available weight loss supplement containing caffeine and magnesium salicylate which can potentiate one another's toxicity: the hypokalaemia caused by the former can be exacerbated by treatment of the salicylism caused by the latter. ${ }^{37}$

- Abuse of caffeine alone poses a risk of myocardial infarction which may present many hours later. ${ }^{38}$

- Common table salt, if ingested in high enough quantities (only a few tablespoons) to induce an osmotic diarrhoea, can cause life-threatening hypernatraemia. ${ }^{39}$

- Less familiar but highly dangerous (and available online) are cardiac glycosides such as 'pong-pong' from South East Asia which has both a reputation for weight loss and suicide. ${ }^{40}$

\section{Hepatic dysfunction}

- Unexplained abnormal liver enzymes in a young patient with weight loss may indicate a diagnosis of AN. ${ }^{4142}$

\section{Fracture risk}

- Young patients with unexpected or low-energy fractures, especially those usually seen in osteoporotic older patients (such as hip or vertebral fractures) may have an undisclosed eating disorder. ${ }^{43}$

\section{Complications of thiamine deficiency}

- Thiamine deficiency is a common sequela of poor nutritional state and can, within a matter of weeks, lead to heart failure which is reversible with nutritional supplementation. ${ }^{44}$

- Wernicke-Korsakoff's syndrome also has reversibility to its neurological manifestations as long as it is promptly and fully treated with high dose thiamine replacement. ${ }^{45}$

\section{Acute gastric dilatation}

- Abdominal pain, tenderness and distension following a bingeeating episode should prompt consideration of acute gastric dilatation; even in restrictive eating disorders, impaired gastric emptying may lead to the same presentation. ${ }^{46-53}$

- The dilated GI tract can generate enough backward-pressure on adjacent structures to induce pancreatitis. ${ }^{46}$

- Compression of surrounding organs and vasculature may also lead to significant ischaemia due to the development of an abdominal compartment syndrome, especially in a group already at risk of superior mesenteric artery syndrome. ${ }^{474854}$

- Large-bore nasogastric tube decompression undertaken without delay after imaging may reverse ischaemia, improve any obstructive kidney injury, avoid progression to gastric necrosis and prevent potential circulatory collapse. ${ }^{46} 495255$

\section{Gastric rupture}

- Gastric necrosis following prolonged abdominal compartment syndrome caused by gastric dilatation may lead to gastric rupture, requiring urgent surgical intervention and gastrectomy. 5556

\section{Ischaemic bowel}

- The small bowel and colon may also become ischaemic following a binge episode, while rare, it carries with it high mortality $^{57}$

\section{Foreign body ingestion}

- Purging behaviour using a long implement such as a spoon, fork or toothbrush should give a clear diagnosis of an 
ingested foreign body (if disclosed) requiring either endoscopic or surgical removal. ${ }^{58} 59$

- There is potential for airway compromise and need for laryngoscopic removal of accidentally misplaced purging implements or large food boluses, while a simple diagnosis, patients may not disclose a clear history of how it occured. ${ }^{6061}$

\section{IMMEDIATE ED MANAGEMENT CONSIDERATIONS}

Simple correction and discharge of a hypokalaemic or hypoglycaemic patient with an eating disorder is only likely to temporise the problem: without either admission or robust ongoing management and follow-up, they will very likely relapse. ${ }^{62}$ Given the overall depleted potassium and glycogen stores it is challenging in the short ED stay to be sure that such a relapse will not prove fatal.

Refeeding syndrome is one important risk discussed below however, if there is hypoglycaemia, this should be promptly addressed with food in the first instance and glucose as necessary with additional vitamin supplementation including thiamine. Care must also be taken with fluid administration given the potential for disease-related structural cardiac dysfunction. ${ }^{63}$

Syncope should be considered in more depth in patients with AN. An obvious cause for this might be hypoglycaemia, however, in other cases, it may indicate underlying cardiac rhythm disturbance, therefore, with any heightened suspicion, a careful re-read of the ECG and a period of monitoring is wise. ${ }^{64}$

If, after full assessment, no medical reason for admission is obtained, there should be a consideration of whether there are psychiatric reasons to admit in which case there should be a low threshold for discussion with the specialist mental health team. If discharge to the community is still deemed appropriate it should be accompanied by clear documentation and communication with the relevant outpatient focal point (possibly eating disorder services or GP) to provide an adequate safety net. Communicating this plan with next of kin is a priority however this can present yet another challenge if the patient does not wish for this to happen. Some effort should be made to gently convince the patient to involve at least someone in their social support network in their discharge planning.

EM/AM practitioners will recognise that this is not a straightforward consultation with some of the specific challenges highlighted in box 4 .

\section{A NUTRITION PERSPECTIVE Nutritional replacement}

In addition to the presenting body weight, multiple other variables need to be considered including:

- The speed of weight loss.

- The number of calories being consumed in the days or weeks prior to presentation.

- Active comorbidities and infections.

EM/AM practitioners should not be aiming to rapidly replenish nutrition in the ED. In fact, because some patients may be in compensated states of malnutrition, caution should be exercised as to what is introduced to a patient in this setting to avoid serious refeeding or fluid overload complications. Refeeding syndrome caused by either introducing or increasing the amount of calories can cause significant metabolic and electrolyte imbalance which can manifest itself as life-threatening hypophosphataemia, hypokalaemia and hypomagnesaemia. ${ }^{28} 65$ Refeeding is usually done under the supervision of experienced dietitians with multimineral and multivitamin supplementation.
Controlled oral or nasogastric tube intake is the preferred route of calorie replenishment in those with severe malnourishment. Therefore (unless immediate hypoglycaemia is being corrected), careful consideration should be given to the inadvertent calorie content of intravenous dextrose solutions especially when being used as a medium for administration of other medications. Thus any nutritional replacement, balancing the risks of refeeding with the continued risk posed by undernutrition, is best done in conjunction with an expert nutrition team as international guidance recommends starting at anything between $5 \mathrm{kcal} / \mathrm{kg} /$ day and $25 \mathrm{kcal} / \mathrm{kg} /$ day. ${ }^{28} 65-68$

If an EM/AM practitioner has decided to admit a patient due to nutritional concerns, then early administration of thiamine, folate and multivitamins would be recommended. An alcohol history is also pivotal as patients with an eating disorder who also have an alcohol dependency are at greater risk of severe vitamin depletion (more common in $\mathrm{BN}$ or $\mathrm{AN}$ binge eating/ purging subtypes). ${ }^{69} 70$

\section{Refeeding syndrome as a presenting complaint}

Patients with eating disorders may present to the ED with significant electrolyte abnormalities because they have already developed refeeding syndrome in the community or as an inpatient in a psychiatric unit without on-site AM facilities. Intravenous thiamine and multivitamins should be given in addition to correcting underlying electrolyte abnormalities. The choice of fluid used to correct electrolytes in these circumstances should be made following specialist advice as the dextrose and sodium content needs to be carefully balanced. ${ }^{71}$

\section{INTERACTION WITH HEALTHCARE PRACTITIONERS}

Negative attitudes towards eating disorders are well documented as healthcare professionals may see this patient group as being responsible for their own difficulties. ${ }^{72} 73$ Research with primary care physicians demonstrated a reluctance to manage eating disorders, alongside some strong negative emotional responses leading to dismissive and trivialising care experiences; this can in turn lead to iatrogenic harm or neglect, increased patient resistance to seeking support, and increased eating disorder behaviours. $^{74} 75$ This can increase the stigma around mental health and demonstrates the importance of clinicians questioning their own beliefs and biases. Clinicians may feel more confident in performing objective medical tests than communicating with the patient and engaging in behavioural management. ${ }^{76}$ This may lead to missed opportunities to support patients within the ED in their referral to specialist eating disorder services.

When clinicians are knowledgeable about eating disorders and demonstrate good interpersonal skills including a compassionate, non-judgemental approach this creates a more positive patient experience. ${ }^{74}$ This may lead to the patient being more open about their difficulties. It has been noted the experience of accessing care is associated with apprehension of losing control therefore it is worthwhile encouraging open dialogue, rather than trying to problem-solve. ${ }^{77} 78$ While the inherent power imbalance between the healthcare system and the patient may provoke anxiety around control being taken away, it can also be seen as a safe-haven in which control is relinquished. ${ }^{74}$ Thus, clinicians should adopt a directive, but not authoritarian approach to patients with eating disorders. In doing so, it becomes less likely that the ED team will need to resort to involuntary treatment as the patient may agree to the acute management plan. 


\section{ADMISSION FOR INVOLUNTARY TREATMENT}

In addition to medical complications, patients with eating disorders may also present with suicidal ideation or following attempted suicide as concurrent depression and suicidality is common. ${ }^{79}$ Navigating admission and treatment has some specific hurdles in this patient group whose underlying psychiatric disorder cannot be separated from their acute presentation. ${ }^{80}$ Patients, therefore, may: refuse admission and try to leave, refuse treatment especially if it involves feeding; and engage in challenging behaviours such as obsessive exercise and self-harm.

Initial steps should determine:

- The patient's capacity to refuse treatment.

- If it is appropriate to give treatment against their will.

- What powers staff have to keep the patient in the department to prevent dangerous consequences.

Most countries have legislation which allows treatment of eating disorders without consent. In England and Wales, for example, the Mental Capacity Act (MCA) (2005) and the Mental Health

Main messages

- Eating disorders are frequently undetected among our acute patients; this is a specific concern in patients with masking comorbidities.

- There are specific features which should immediately lower threshold for admission or further investigation of eating disorders.

- Appreciating the interplay between all aspects of the patient presentation - medical, nutritional, psychiatric, psychological and ethical-is likely to result in a safer approach to such patients.

Current research questions

- What impact does improved clinician education on eating disorders have on the outcomes of those patients attending emergency departments?.

- Can the Sit up-Squat Stand test be used as a valid screening tool for anorexia nervosa in the emergency department?.

- What is emergency/acute clinician understanding of the role of mental capacity in decision to discharge against medical advice in those patients with anorexia nervosa?.

\section{Key references}

- RCPSYCH. MARSIPAN: Management of Really Sick Patients with Anorexia Nervosa. 2014.

- Arcelus J, Mitchell AJ, Wales J, et al. Mortality rates in patients with anorexia nervosa and other eating disorders. A metaanalysis of 36 studies. Arch Gen Psychiatry 2011;68:724-31

- Dooley-Hash S, Lipson SK, Walton MA, et al. Increased emergency department use by adolescents and young adults with eating disorders. Int J Eat Disord 2013;46:308-15

- Ali K, Farrer L, Fassnacht DB, et al. Perceived barriers and facilitators towards help-seeking for eating disorders: A systematic review. Int J Eat Disord 2017;50:9-21.

- Cave E, Tan J. Severe and enduring anorexia nervosa in the Court of Protection in England and Wales. International Journal of Mental Health and Capacity Law. 2017;23:4-24.
Self assessment questions

Q1 Anorexia nervosa is has the highest mortality rate of all mental health conditions

- True

- False

Q2 Having type I diabetes is a protective factor for the mortality rate of those with anorexia nervosa

- True

- False

Q3 In anorexia nervosa, a heart rate of $39 \mathrm{bpm}$ is an indication for admission

- True

- False

Q4 If someone with an eating disorder is symptomatic of hypoglycaemia, treatment of the hypoglycaemia should be delayed until full assessment and expert opinion has been obtained

- True

- False

Q5 You deem a patient with an eating disorder is seriously ill and needs admission for treatment and they refuse to see any other professional or remain in hospital, you therefore assess their capacity and feel they meet the criteria for mental capacity. You document this assessment and their wishes and should now discharge them.

- True

- False

\section{Answers}

- True

- False

- True

- False

- False

Act (MHA) ((2007) provide a framework for assessment. ${ }^{81} 82$ The precise detail of mental health legislation varies internationally. However global guidance is available from the WHO standards based on the universal declaration on human rights where a careful balance must be struck between: maintaining patient autonomy/avoiding abuse of power, and the need to be able to protect the well-being of a patient suffering with a mental health condition. All of these considerations are important, while ensuring that healthcare professionals offer treatment in the patients' best interests. ${ }^{83}$

In the case where a patient with an eating disorder warrants admission from the ED, due to physical complications of their condition, it is likely that the criteria of 'serious threat to health' is met. In England and Wales, the MCA (2005) and its related legislation is more commonly used in acute inpatient settings and EM practitioners in particular may be more comfortable applying legislation for incapacity. In the case of eating disorders, it is possible that patients may have impaired capacity, however detecting this is not straightforward. ${ }^{84}$ Many patients with eating disorders, even if making a decision most would deem irrational, have the intellectual capacity to understand the risks and benefit 
of treatment and communicate a decision and the complexities of this, which makes capacity assessment fraught with difficulty. ${ }^{85}$ Therefore, as the patient is fundamentally suffering from a mental disorder (to use the terminology of the MHA) and their health cannot be preserved without treatment, the MHA (2007) is likely to be a more appropriate route to compulsory hospitalisation in England and Wales. ${ }^{81}$ To be detained under the MHA a patient must fulfil three criteria:

- Have a mental disorder which requires treatment as an inpatient.

- Inpatient management is necessary for the health and safety of the patient/others.

- There is treatment available.

Nasogastric feeding and associated interventions for example, blood tests and correction of electrolytes are considered medical treatment under the act. A patient suffering severe AN presenting to the ED would likely meet these criteria. However, the ED is not an inpatient setting and therefore in the UK a patient suffering severe AN who is not accepting treatment in any form needs swift discussion with the liaison or eating disorder mental health team to ensure the appropriate compulsory treatment can be enacted to both assess and treat without consent.

Many countries do not take this binary approach to mental incapacity and mental health legislation. In Scotland, the Mental Health (Care and Treatment) (Scotland) Act 2003 incorporates an 'impaired decision-making criterion': that a patient must in some way lack capacity to be detained under mental health legislation. ${ }^{86}$ Other parts of North America and Europe take a hybrid legal position which applies similar reasoning of the MHA (2007) for detention of patients but additionally an incapacity criterion, to treatment of these patients. ${ }^{87}$

\section{Capacity: a specific challenge}

If required to assess compulsory hospitalisation of an eating disorder patient on the basis of capacity it is important to consider certain factors that may be unique to eating disorders. First, a person with an eating disorder may initiate behaviours and then feel compelled to maintain them and others may view them as both the perpetrator and victim of their condition. ${ }^{88}$ Eating disorders can also affect a person's values and personal identity which can make it difficult for them to differentiate their genuine wishes and desires from the drive of the disorder or to decide they wish to recover, even if they are able to articulate an apparently rational thought process. ${ }^{89}$

Second, people with severe eating disorders may present with an apparent lack of motivation regarding treatment and recovery due to their need to retain control, a strong drive to continue to lose weight, or an inability to apply the facts to themselves: yet even so they often retain an ability to reason. These factors may lead to a superficial appearance of capacity but when explored, many of these patients may lack capacity to make decisions about treatment for their eating disorder. This has been underlined by Court of Protection cases which have found patients with severe AN to lack capacity to make decisions about the treatment of their eating disorders. ${ }^{90}$ The importance of involving healthcare professionals who have in-depth understanding and specific experience of eating disorders when risks to health are severe, but patients appear to have capacity and are refusing treatment, cannot be overstated.

\section{SUMMARY}

Eating disorders are a challenge to the EM and AM clinician on almost every level. They require some understanding of physiological, anatomical, biochemical, psychological, psychiatric and legal implications. They also mandate an understanding of community and inpatient structures of management. With some focused education and robust management pathways those in the acute setting have an opportunity to alter the outcome of the most severely unwell patients with $\mathrm{AN}$ and contribute to reducing morbidity and mortality in the most deadly of mental health conditions.

Twitter Anisa Jabeen Nasir Jafar @EmergeMedGlobal and Wisam Jalal Jawad Jafar @GastroNW

Acknowledgements We thank Dr Ellen Weber for her advice on the content of this article

Contributors AJNJ planned the work. AJNJ, WJJJ, EKE, IG, HMS and JT wrote the content. AJNJ, WJJJ, EKE, IG, HMS and JT reviewed and edited the final manuscript. AJNJ submitted the work. AJNJ is the guarantor of the work.

Funding The authors have not declared a specific grant for this research from any funding agency in the public, commercial or not-for-profit sectors.

Competing interests None declared.

Patient consent for publication Not applicable.

Provenance and peer review Not commissioned; externally peer reviewed.

Open access This is an open access article distributed in accordance with the Creative Commons Attribution Non Commercial (CC BY-NC 4.0) license, which permits others to distribute, remix, adapt, build upon this work non-commercially, and license their derivative works on different terms, provided the original work is properly cited, appropriate credit is given, any changes made indicated, and the use is non-commercial. See: http://creativecommons.org/licenses/by-nc/4.0/.

\section{ORCID iD}

Anisa Jabeen Nasir Jafar http://orcid.org/0000-0001-9262-1450

\section{REFERENCES}

1 PHSO. Ignoring the alarms: how NHS eating disorder services are failing patients, 2017.

2 RCEM. Safety flash - Anorexia Nervosa, 2020. Available: https://www.rcem.ac.uk// docs/Safety/RCEM\%20Safety\%20Flash_ANOREXIA\%20NERVOSA_FINAL2020.pdf

3 Dooley-Hash S, Lipson SK, Walton MA, et al. Increased emergency department use by adolescents and young adults with eating disorders. Int J Eat Disord 2013;46:308-15

4 Treasure J, Russell G. The case for early intervention in anorexia nervosa: theoretical exploration of maintaining factors. Br J Psychiatry 2011;199:5-7.

5 Lakeman R, McIntosh C. Perceived confidence, competence and training in evidencebased treatments for eating disorders: a survey of clinicians in an Australian regional health service. Australas Psychiatry 2018;26:432-6.

6 Hugo P, Kendrick T, Reid F. Gp referral to an eating disorder service: why the wide variation? Br J Gen Pract 2000;50:380-3.

7 Ayton A, Ibrahim A. Does UK medical education provide doctors with sufficient skills and knowledge to manage patients with eating disorders safely? Postgrad Med J 2018:94:374-80.

$8 \mathrm{Ma} \mathrm{C}$, Gonzales-Pacheco D, Cerami J, et al. Emergency medicine physicians' knowledge and perceptions of training, education, and resources in eating disorders. $J$ Eat Disord 2021;9:4.

9 Li L. Challenges and priorities in responding to COVID-19 in inpatient psychiatry. Psychiatr Serv 2020;71:624-6.

10 Robertson M, Duffy F, Newman E, et al. Exploring changes in body image, eating and exercise during the COVID-19 lockdown: a UK survey. Appetite 2021;159:105062.

11 WHO. Icd-11 for mortality and morbidity statistics: feeding or eating disorders, 2018. Available: https://icd.who.int/browse11/l-m/en\#/http\%3A\%2F\%2Fid.who.int\% 2Ficd\%2Fentity\%2F1412387537

12 Claudino AM, Pike KM, Hay P, et al. The classification of feeding and eating disorders in the ICD-11: results of a field study comparing proposed ICD-11 guidelines with existing ICD-10 guidelines. BMC Med 2019;17:93.

13 Arcelus J, Mitchell AJ, Wales J, et al. Mortality rates in patients with anorexia nervosa and other eating disorders. A meta-analysis of 36 studies. Arch Gen Psychiatry 2011;68:724-31

14 Sullivan PF. Mortality in anorexia nervosa. Am J Psychiatry 1995;152:1073-4.

15 Solmi F, Hatch SL, Hotopf M, et al. Prevalence and correlates of disordered eating in a general population sample: the South East London community health (SELCOH) study. Soc Psychiatry Psychiatr Epidemiol 2014;49:1335-46.

16 BEAT. How many people have an eating disorder in the UK? 2021. Available: https:// www.beateatingdisorders.org.uk/get-information-and-support/about-eatingdisorders/how-many-people-eating-disorder-uk/ 
17 Oldershaw A, Startup H, Lavender T. Anorexia nervosa and a lost emotional self: a psychological formulation of the development, maintenance, and treatment of anorexia nervosa. Front Psychol 2019;10:219.

18 Blythin SPM, Nicholson HL, Macintyre VG, et al. Experiences of shame and guilt in anorexia and Bulimia nervosa: a systematic review. Psychol Psychother 2020;93:134-59.

19 Ali K, Farrer L, Fassnacht DB, et al. Perceived barriers and facilitators towards helpseeking for eating disorders: a systematic review. Int J Eat Disord 2017;50:9-21.

20 Aya V, Ulusoy K, Cardi V. A systematic review of the 'eating disorder voice' experience. Int Rev Psychiatry 2019;31:347-66.

21 Pugh M, Waller G, Esposito M. Childhood trauma, dissociation, and the internal eating disorder 'voice'. Child Abuse Neg/ 2018;86:197-205.

22 Seitz J, Herpertz-Dahlmann B, Konrad K. Brain morphological changes in adolescent and adult patients with anorexia nervosa. J Neural Transm 2016;123:949-59.

23 Hay P, Touyz S. Treatment of patients with severe and enduring eating disorders. Curr Opin Psychiatry 2015;28:473-7.

24 Nielsen S, Emborg C, Mølbak A-G. Mortality in concurrent type 1 diabetes and anorexia nervosa. Diabetes Care 2002;25:309-12.

25 Tan JO, Spector-Hill I. Identifying and managing eating disorders in type 1 diabetes mellitus: an all-Wales study. Clin Child Psychol Psychiatry 2021;26:617-28.

26 Kutz AM, Marsh AG, Gunderson CG, et al. Eating disorder screening: a systematic review and meta-analysis of diagnostic test characteristics of the SCOFF. J Gen Intern Med 2020;35:885-93.

27 Robinson P. Avoiding deaths in hospital from anorexia nervosa: the MARSIPAN project. Psychiatrist 2012;36:109-13.

28 RCPSYCH. MARSIPAN: management of really sick patients with anorexia nervosa, 2014

29 Bouquegneau A, Dubois BE, Krzesinski J-M, et al. Anorexia nervosa and the kidney. Am J Kidney Dis 2012;60:299-307.

30 Gren J, Woolf A. Hypermagnesemia associated with catharsis in a salicylateintoxicated patient with anorexia nervosa. Ann Emerg Med 1989;18:200-3.

31 Seidler $\mathrm{T}$, Jacobshagen C, Bauer M, et al. Distribution of potassium levels on admission for CPR--severe hypokalaemia with dysmorphophobic eating disorders. Resuscitation 2011:82:535-7.

32 Boyd ED, Durant NH. Recurrent hyponatremia in a young adult woman with anorexia nervosa and the effects of insufficient communication. Int J Eat Disord 2018:51:1378-81.

33 Grover CA, Robin JK, Gharahbaghian L. Anorexia nervosa: a case report of a teenage presenting with bradycardia, general fatigue, and weakness. Pediatr Emerg Care 2012;28:174-7

34 Bonnemeier $\mathrm{H}$, Mall G, Wiegand UKH. Sudden cardiac death due to catecholamine cardiomyopathy in anorexia nervosa. Resuscitation 2006;68:9-10.

35 Di Cola G, Jacoangeli F, Jacoangeli F, et al. Cardiovascular disorders in anorexia nervosa and potential therapeutic targets. Intern Emerg Med 2014;9:717-21.

36 Buchanan R, Ngwira J, Amsha K. Prolonged QT interval in Bulimia nervosa. BMJ Case Rep 2011:2011:bcr0120113780.

37 Berger RE, Ganetsky M. An over-the-counter weight-loss supplement with a toxicity that may be unexpectedly difficult to treat. Intern Emerg Med 2012;7 Suppl 2:91-2.

38 Forman J, Aizer A, Young CR. Myocardial infarction resulting from caffeine overdose in an anorectic woman. Ann Emerg Med 1997:29:178-80.

39 Hancher J, Fisher J, Shenvi C. Severe hypernatremia and gastric dilation from chronic eating disorder and intentional salt ingestion. Am J Emerg Med 2020;38:1700. e1-1700.e3

40 Nordt SP, Hendrickson M, Won K, et al. Death from cardiac glycoside "pong-pong" following use as weight-loss supplement purchased on Internet. Am J Emerg Med 2020;38:1698.e5-1698.e6.

41 Karahmadi M, Layegh $\mathrm{E}$, Layegh $\mathrm{S}$, et al. High level increase in liver enzymes and severe thrombocytopenia in a male case of anorexia nervosa( $\left.{ }^{*}\right)$. J Res Med Sci 2011:16:1378-81.

42 Jafar W, Morgan J. Anorexia nervosa and the gastrointestinal tract. Frontline Gastroenterol 2021:3:flgastro-2021-101857.

43 Park JS, Lee HS, Won SH, et al. Intertrochanteric fracture with low-energy trauma in a young woman with anorexia nervosa: a case report. Medicine 2019;98:e16499.

44 Ward KE, Happel KI. An eating disorder leading to wet beriberi heart failure in a 30-year-old woman. Am J Emerg Med 2013;31:460.e5-460.e6.

45 Altinyazar V, Kiylioglu N, Salkin G. Anorexia nervosa and Wernicke Korsakoff's syndrome: atypical presentation by acute psychosis. Int J Eat Disord 2010;43:766-9.

$46 \mathrm{Kim} \mathrm{HH}$, Park SJ, Park MI, et al. Acute gastric dilatation and acute pancreatitis in a patient with an eating disorder: solving a chicken and egg situation. Intern Med 2011:50:571-5.

47 Van Eetvelde E, Verfaillie L, Van De Winkel N, et al. Acute gastric dilatation causing acute limb ischemia in an anorexia nervosa patient. J Emerg Med 2014:46:e141-3.

48 Kashyap AS, Chopra D, Anand KP, et al. Acute gastric dilatation. Emerg Med J 2009;26:326.

49 Repessé X, Bodson L, Au S-M, et al. Gastric dilatation and circulatory collapse due to eating disorder. Am J Emerg Med 2013;31:633.e3-633.e4.

50 Pasin F, Modoni A, Teti L, et al. Massive gastric dilatation: the radiological picture of eating disorder. Intern Emerg Med 2017;12:119-21.
51 Kim S-C, Cho H-J, Kim M-C, et al. Sudden cardiac arrest due to acute gastric dilatation in a patient with an eating disorder. Emerg Med J 2009;26:227-8.

52 Dumouchel J, Lvovschi V, Joly L-M. Obstructive acute renal failure by severe gastric distension after binge. Am J Emerg Med 2017;35:1210.e5-1210.e7.

53 Lemke J, Scheele J, Schmidt S, et al. Massive gastric dilatation caused by eating binges demanding surgical intervention: a case report. GMS Interdiscip Plast Reconstr Surg DGPW 2014;3:Doc09

54 Verhoef PA, Rampal A. Unique challenges for appropriate management of a 16-yearold girl with superior mesenteric artery syndrome as a result of anorexia nervosa: a case report. J Med Case Rep 2009;3:127.

55 Achamrah N, Grigioni S, Coëffier M, et al. Gastric necrosis after binge eating in bulimia: recovery from eating disorder after total gastrectomy. Front Psychiatry 2020;11:741.

56 Morse JL, Safdar B. Acute tension pneumothorax and tension pneumoperitoneum in a patient with anorexia nervosa. J Emerg Med 2010;38:e13-16.

57 Foran AT, Clancy C, Gorey TF. Case report of the surgical management of small bowel and colonic ischaemia associated with anorexia nervosa binge/purge subtype. Int $J$ Surg Case Rep 2016;29:238-40.

58 Sankey C, Ladizinski B, Gaudiani JL. Ingested foreign body associated with Bulimia nervosa. J Emerg Med 2014;47:e107-8.

59 Slim R, Geagea A, Yaghi C, et al. Unusual way of purging. Emerg Med J 2006;23:486

60 Jones TM, Luke LC. Life threatening airway obstruction: a hazard of concealed eating disorders. J Accid Emerg Med 1998;15:332-3.

61 Pastoors MM, van Leuken MH, de Jager CPC. An unexplained cardiac arrest, always re-check the "A" after resuscitation. Resuscitation 2013;84:e123-4.

62 Winston AP. The clinical biochemistry of anorexia nervosa. Ann Clin Biochem 2012;49:132-43.

63 Spaulding-Barclay MA, Stern J, Mehler PS. Cardiac changes in anorexia nervosa. Cardiol Young 2016;26:623-8

64 Sachs KV, Harnke B, Mehler PS, et al. Cardiovascular complications of anorexia nervosa: a systematic review. Int J Eat Disord 2016;49:238-48.

65 da Silva JSV, Seres DS, Sabino K, et al. Aspen consensus recommendations for refeeding syndrome. Nutr Clin Pract 2020;35:178-95.

66 IRSPEN. Prevention and treatment of refeeding syndrome in the acute care setting, 2013.

67 NationalCollaboratingCentreforAcuteCare(UK). Nutrition support for adults: oral nutrition support, enteral tube feeding and parenteral nutrition, 2006.

68 Hay P, Chinn D, Forbes D, et al. Royal Australian and New Zealand College of Psychiatrists clinical practice guidelines for the treatment of eating disorders. Aust N Z J Psychiatry 2014;48:977-1008.

69 Bulik CM, Klump KL, Thornton L, et al. Alcohol use disorder comorbidity in eating disorders: a multicenter study. J Clin Psychiatry 2004;65:1000-6.

70 Krug I, Pinheiro AP, Bulik C, et al. Lifetime substance abuse, family history of alcohol abuse/dependence and novelty seeking in eating disorders: comparison study of eating disorder subgroups. Psychiatry Clin Neurosci 2009;63:82-7.

71 Nightingale J, Turner P, De Silva A. Top tips for preventing and managing refeeding syndrome, 2018.

72 Dimitropoulos G, Freeman VE, Muskat S, et al. "You don't have anorexia, you just want to look like a celebrity": perceived stigma in individuals with anorexia nervosa. $J$ Ment Health 2016:25:47-54.

73 Thompson-Brenner H, Satir DA, Franko DL, et al. Clinician reactions to patients with eating disorders: a review of the literature. Psychiatr Serv 2012;63:73-8.

74 Johns G, Taylor B, John A, et al. Current eating disorder healthcare services - the perspectives and experiences of individuals with eating disorders, their families and health professionals: systematic review and thematic synthesis. BJPsych Open 2019;5:e59

75 Graham MR, Tierney S, Chisholm A, et al. The lived experience of working with people with eating disorders: a meta-ethnography. Int J Eat Disord 2020:53:422-41.

76 Davidson AR, Braham S, Dasey L, et al. Physicians' perspectives on the treatment of patients with eating disorders in the acute setting. J Eat Disord 2019:7:1.

77 Gulliksen KS, Nordbø RHS, Espeset EMS, et al. The process of help-seeking in anorexia nervosa: patients' perspective of first contact with health services. Eat Disord 2015:23:206-22.

78 Tan JOA, Hope T, Stewart A, et al. Control and compulsory treatment in anorexia nervosa: the views of patients and parents. Int J Law Psychiatry 2003:26:627-45.

79 National Guideline Alliance (UK). Eating disorders: recognition and treatment, 2017.

80 Garfinkel P, Garner D, Kennedy S. Special problems of inpatient management. In: Gardner D, Garfinkel P, eds. Handbook of psychotherapy for anorexia nervosa and Bulimia. Guiford Press, 1985

81 Mental health act 2007

82 Mental capacity act 2005

83 Fistein EC, Holland AJ, Clare ICH, et al. A comparison of mental health legislation from diverse Commonwealth jurisdictions. Int J Law Psychiatry 2009:32:147-55.

84 Adoue $C$, Jaussent I, Olié $\mathrm{E}$, et al. A further assessment of decision-making in anorexia nervosa. Eur Psychiatry 2015;30:121-7.

85 Tiller J, Schmidt U, Treasure J. Compulsory treatment for anorexia nervosa: compassion or coercion? Br J Psychiatry 1993;162:679-80. 
86 Szmukler G, Daw R, Dawson J. A model law fusing incapacity and mental health legislation. Special Ed J Mental Health L 2010.

87 Dawson J, Szmukler G. Fusion of mental health and incapacity legislation. $\mathrm{Br} J$ Psychiatry 2006;188:504-9.

88 Giordano S. Understanding eating Disorders- conceptual and ethical issues in the treatment of anorexia and Bulimia nervosa. Oxford University Press on Demand, 2005.

89 Tan JOA, Hope T, Stewart A. Anorexia nervosa and personal identity: the accounts of patients and their parents. Int I Law Psychiatry 2003;26:533-48.
90 Cave E, Tan JOA. Severe and enduring anorexia nervosa in the court of protection in England and Wales. International Journal of Mental Health and Capacity Law 2017;2017:4-24.

91 HAS. Anorexie mentale : prise en charge 3 - Critères d'hospitalisation temps plein, 2010.

92 Yager J, Devlin M, Halmi K. Practice guideline for the treatment of patients with eating disorders, 2006.

93 Mascolo M, Trent S, Colwell C, et al. What the emergency department needs to know when caring for your patients with eating disorders. Int J Eat Disord 2012;45:977-81. 